\title{
Lifestyle, psychological stress, and incidence of adolescent constipation: results from the Toyama birth cohort study
}

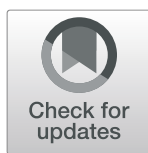

\author{
Masaaki Yamada $^{1 *}$ (D) Michikazu Sekine ${ }^{1}$, Takashi Tatsuse ${ }^{1}$ and Yuko Fujimura ${ }^{2}$
}

\begin{abstract}
Background: We aimed to clarify the predisposing factors for adolescent constipation in a longitudinal study, because while factors associated with childhood constipation have been reported, prospective studies on the incidence of constipation are lacking.

Methods: We enrolled 5540 adolescents aged 12 to 13 years from the Toyama Birth Cohort Study - a communitybased prospective study examining children's health. The incidence of constipation, defined as bowel movement frequency of less than once every 2 days, was surveyed during the three-year period from baseline (grade 4) to follow-up (grade 7). Multivariate logistic regression analyses were performed to explore the association between the incidence of adolescent constipation and their lifestyle variables.

Results: A total of 261 adolescents (4.7\%) developed constipation during the three-year period. Female sex (odds ratio $[O R]=2.62$, ) overweight $(O R=0.60)$, and infrequent intake of fruits $(O R=1.50)$ at baseline were associated with the incidence of constipation. Furthermore, factors related to lifestyle changes and psychological status such as skipping breakfast $(\mathrm{OR}=1.73)$, becoming physically inactive $(\mathrm{OR}=1.55)$, and being persistently irritated $(\mathrm{OR}=1.80)$ were significantly associated with the incidence of constipation.

Conclusion: Our prospective study demonstrated that female sex, insufficient fruit intake, and deteriorating lifestyles such as skipping breakfast and becoming inactive during the 3-year period were associated with the incidence of adolescent constipation. Beyond anecdotal, maintaining a healthy lifestyle is recommended to reduce the incidence of adolescent constipation.
\end{abstract}

Keywords: Lifestyle change, Bowel movement, Physical activity, Breakfast, Predisposing factors

\section{Background}

Constipation is common, with a prevalence ranging from 0.5 to $32.2 \%$ in children aged 0 to 18 years [1]. In many cases, the prognosis is not always good $[2,3]$. For instance, Loening-Baucke reported that among $94 \%$ of patients, constipation recurred immediately after laxative discontinuation [2]. Bongers et al. showed that

\footnotetext{
* Correspondence: masaakit@med.u-toyama.ac.jp

'Department of Epidemiology and Health Policy, School of Medicine, University of Toyama, Toyama, Japan. 2630 Sugitani, Toyama 930-0194, Japan Full list of author information is available at the end of the article
}

constipation persisted into adulthood in approximately $25 \%$ of children [3]. Moreover, constipation has a negative impact on both individuals and society as a whole. It causes acute abdominal pain and decreases patients' quality of life $[4,5]$. Additionally, it results in 2.5-million physician visits annually and contributes to considerable healthcare financial burden in the American society [6]. Thus, childhood constipation should be considered a major public health problem.

Several risk factors, such as insufficient fiber intake, genetic predisposition, physical inactivity, and

(c) The Author(s). 2021 Open Access This article is licensed under a Creative Commons Attribution 4.0 International License, which permits use, sharing, adaptation, distribution and reproduction in any medium or format, as long as you give appropriate credit to the original author(s) and the source, provide a link to the Creative Commons licence, and indicate if changes were made. The images or other third party material in this article are included in the article's Creative Commons licence, unless indicated otherwise in a credit line to the material. If material is not included in the article's Creative Commons licence and your intended use is not permitted by statutory regulation or exceeds the permitted use, you will need to obtain permission directly from the copyright holder. To view a copy of this licence, visit http://creativecommons.org/licenses/by/4.0/ The Creative Commons Public Domain Dedication waiver (http://creativecommons.org/publicdomain/zero/1.0/) applies to the data made available in this article, unless otherwise stated in a credit line to the data. 
psychological stress, have been identified for childhood constipation [1, 7], but most were inferred from cross-sectional studies. We previously reported that psychological stress and less frequent parental interaction were as strongly associated with constipation as dietary factors [8]. To clarify the predisposing factors, a prospective cohort study is needed to assess the incidence of constipation among children, especially adolescents who are starting to establish their lifestyle, which they will continue during into adulthood.

The existing few prospective studies on childhood constipation have primarily focused on its prognoses $[2,3,9]$, such as recovery or success rate in clinical settings. Bongers et al. demonstrated that the onset of childhood constipation at an older age was associated with poor clinical outcomes in adulthood [3]. However, prospective studies exploring constipation incidence among older children are lacking. We hypothesized that elucidating predisposing factors of adolescent constipation could decrease the incidence of constipation, thereby easing the social burden placed on the health care system.

Thus, we performed a school-based prospective study among Japanese adolescents to provide data on the incidence of adolescent constipation. To our knowledge, this is the first and largest study assessing the predisposing factors of adolescent constipation.

\section{Methods}

\section{Study participants}

This study included children from the Toyama Birth Cohort Study, a longitudinal survey (a repeated open cohort style) examining lifestyle and health in 10,438 children born in Toyama Prefecture, Japan, between April 2, 1989 and April 1, 1990. The school children had been examined via a questionnaire every 3 years from Phase 1 in 1992 to Phase 5 in 2005. The details of the study have been described elsewhere $[8,10-$ 13]. The institutional review board at Toyama Medical and Pharmaceutical University (current University of Toyama) and the prefecture education authorities approved the current study.

\section{Questionnaire at baseline}

The Toyama Birth Cohort Study Phase 3 was conducted in July 1999, when the cohort of children were in grade 4 in elementary schools (aged 9-10 years) $[8,10]$. We defined Phase 3 as the baseline survey. The questionnaire included four main areas: lifestyle, including physical activity and food consumption frequency; psychological status; child-parent interaction; and health status such as anthropometric data and bowel movements. (Additional file 1) Children answered questions on their lifestyle, psychological status, child-parent interaction at home, and bowel movements, meanwhile, their parents responded regarding their children's food consumption frequency and anthropometric data. The lifestyle items included breakfast (the answer was dichotomized into "every day" or "skipping"), physical activity ("active" or "inactive"), and watching TV on weekdays $(<2,<3$, or $\geq 3 \mathrm{~h})$. We divided sleep duration into two categories $(<8$ or $\geq 8 \mathrm{~h})$, referring to the average sleep duration of Japanese elementary school children $(8.5 \mathrm{~h}$ per night) [14]. We defined $<8 \mathrm{~h}$ sleep a day in grade 4 children as "short sleep." We also asked food consumption frequency about fruits and vegetables. Our lifestyle questionnaire was validated in previous studies. The frequent physical activity significantly correlated with increased energy expenditure measured by the Actiwatch-L (Mini Mitter Company, Inc., Bend, OR) [15]. The correlation coefficient between subjective and objective records of sleep duration was $0.97(p<0.001)$ [16] . Weight and height were measured by trained school nurses at the children's schools and body mass index (BMI) was calculated. Age- and sex-specific cutoff points $\left(19.46 \mathrm{~kg} / \mathrm{m}^{2}\right.$ for boys and $19.45 \mathrm{~kg} / \mathrm{m}^{2}$ for girls), which were equivalent to the adult BMI value of $25 \mathrm{~kg} /$ $\mathrm{m}^{2}$, were used to define children who were overweight [17]. We asked three questions on children's psychological status and parent-children's interaction. The answers were from four options: often, sometimes, rarely, and none; then, the former and latter two responses were combined into a category, "not rare(ly)" and "rare(ly)" in Table 3, respectively.

\section{Definition of constipation}

The definition of constipation ranges from self-reported to the fulfillment of clinical criteria including bowel movement frequency and symptoms [6,7]. In our epidemiological study, we focused on only bowel movement frequency. The answer was classified into three categories: at least once daily, once every 2 days, or less frequently than once every 2 days. Then, bowel movements less frequently than once every 2 days were defined as constipation, because this corresponds to the Rome IV criterion of "two or fewer defecations in the toilet per week" $[7,18]$.

\section{Questionnaire at follow-up}

In July 2002, three years after the baseline survey, we followed up the children at the Toyama Birth Cohort Study Phase 4, when they were adolescents in grade 7 (aged 12 to 13 years) [11]. Lifestyle at follow-up included skipping breakfast, physical activity, watching TV, and sleep duration. Sleep duration was dichotomized into two categories $(<7$ or $\geq 7 \mathrm{~h}$ ) on weekdays, and $<7 \mathrm{~h}$ sleep duration was defined as "short sleep" considering children's growth. Adolescents with BMI values exceeding 
the cutoff points $\left(21.56 \mathrm{~kg} / \mathrm{m}^{2}\right.$ for male and $22.14 \mathrm{~kg} / \mathrm{m}^{2}$ for female) were classified as overweight [17]. Regarding psychological status and parent-children interaction, the same three questions at baseline were used.

Changes in lifestyle, psychological status, overweight, and parent-children interaction

To clarify the importance of changes in lifestyle, psychological status, overweight, and child-parent interaction during the three years on the incidence of adolescent constipation, we divided the changes into four categories, such as "healthy to healthy," "healthy to unhealthy," "unhealthy to healthy," or "unhealthy to unhealthy."

\section{Statistical analysis}

Baseline characteristics of the distributions of lifestyle, overweight, psychological status, and children-parent interaction among the cohort of children were reported. Comparisons between adolescents with complete followup data and those who dropped out were conducted by chi-squared tests. Next, we conducted logistic regression analysis to clarify the predisposing factors of constipation and to assess the impact of changes in lifestyle, psychological status, overweight, and children-parent interaction on constipation incidence. We calculated crude and adjusted odds ratios (ORs) and 95\% confidence intervals (CIs). We adopted a forced-entry method and all independent variables (shown in Tables 2 and 3) were simultaneously included in the multivariate models. All analyses were performed with SPSS, version $25.0 \mathrm{~J}$ (SPSS, Chicago, IL, USA). A two-tailed $p$-value $<0.05$ was considered to be significant.

\section{Results}

In total, 9378 cohort children were included in the baseline survey. After excluding children who did not return all relevant questionnaires and had already been constipated, 7858 children were followed. The flow of participants in the study is shown in Fig. 1. Finally, 5540 children (male 2844, 51.3\%) who answered all questionnaires at the follow-up survey were deemed eligible (follow-up rate, 70.5\%). Characteristics of children at baseline and (adolescents) follow-up are presented in Table 1. Follow-up bias between adolescents who were finally included in our analyses and those excluded was assessed on the incidence of constipation and lifestyle factors. There were no significant differences in the incidence of constipation, consumption of vegetables and fruits, and physical activity between the two groups.

Table 2 shows the logistic regression analysis results on overall constipation incidence. Over three years, 261 adolescents developed constipation (incidence, 4.7\%). In the univariate analysis, female sex, watching TV for $<3 \mathrm{~h}$, infrequent consumption of fruits, being overweight (inversely), and frequent irritability at baseline were associated with constipation incidence. In the multivariate analysis, female sex (OR 2.62; 95\% CI, 1.99-2.62), being overweight (OR 0.60; 95\% CI, 0.40-0.91), and infrequent consumption of fruits (OR 1.50; 95\% CI, 1.08-2.09 for 02 times/week) remained factors significantly associated with constipation incidence. ORs for the difference in constipation between males and females were hardly changed in the univariate and multivariate analyses.

Table 3 shows the impact of the changes in lifestyle, overweight, psychological status, and childparent interaction during the three years on the incidence of adolescent constipation from the logistic

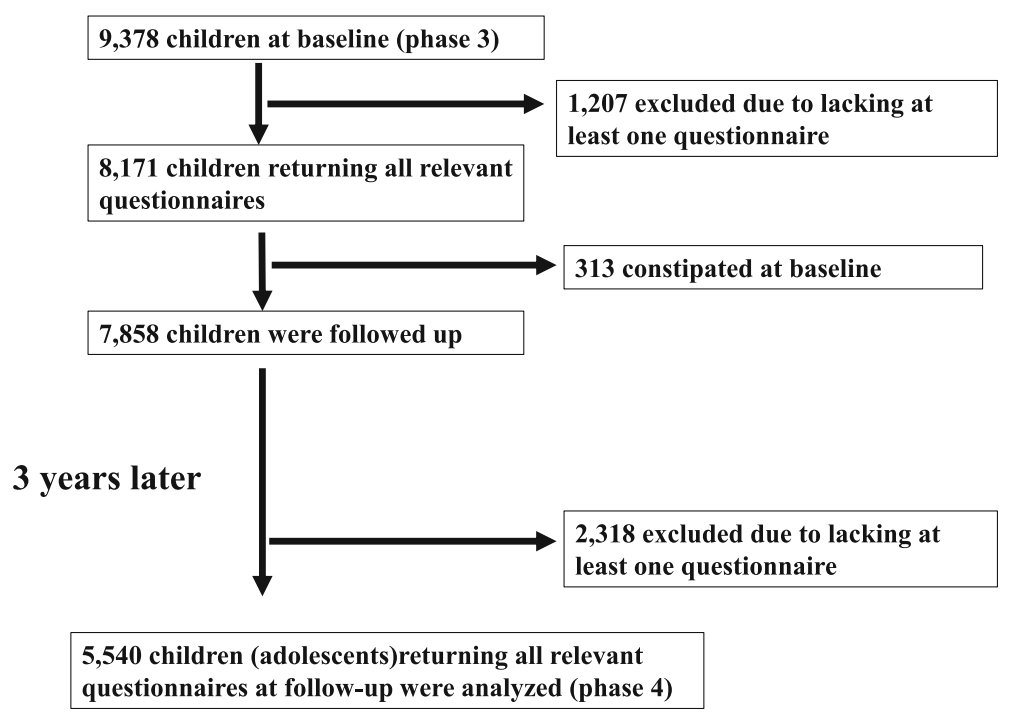

Fig. 1 The flow of participants on the cohort study 
Table 1 Characteristics of children at baseline (Phase 3) and follow-up (Phase 4)

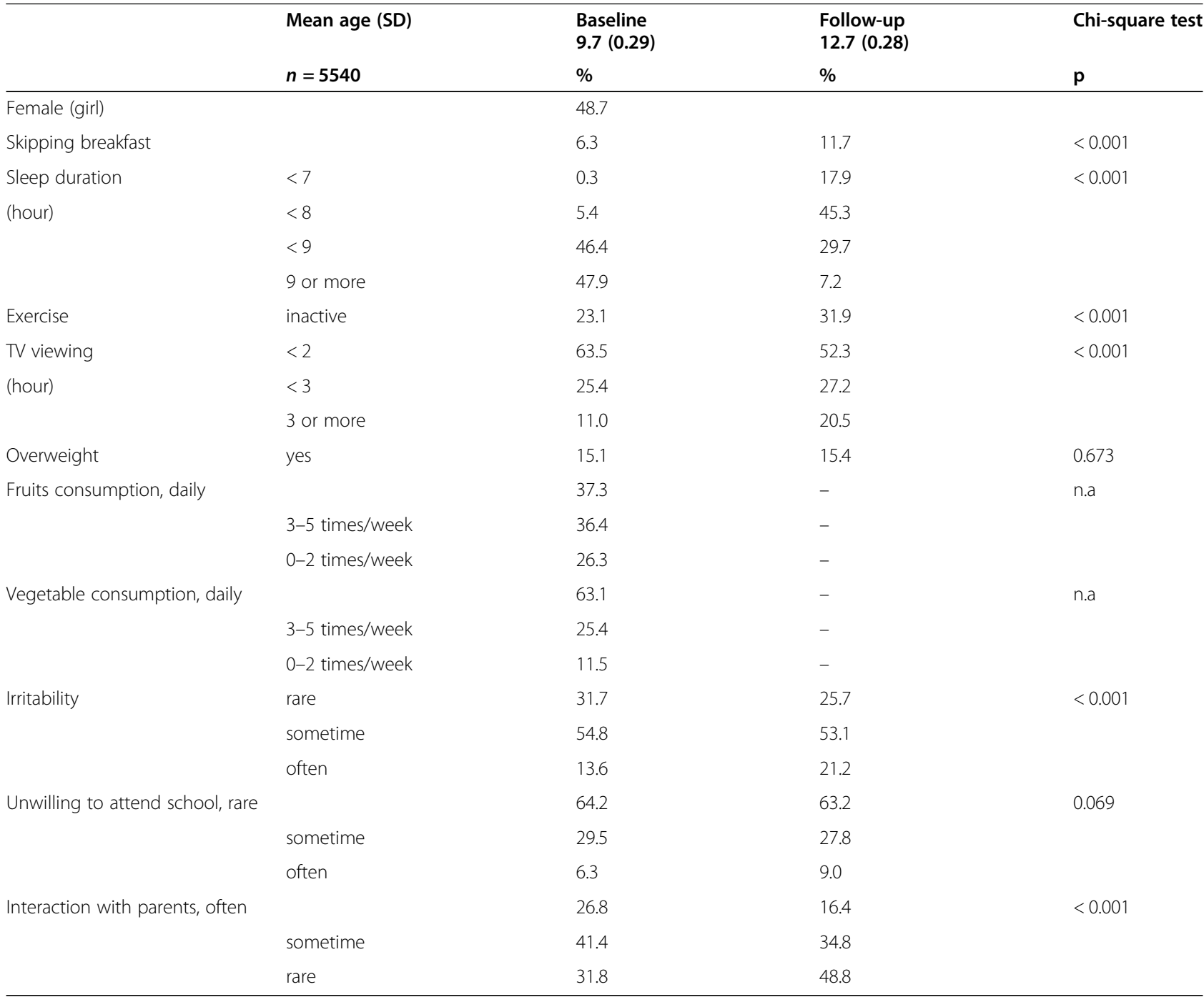

n.a not applicable

regression analysis. In the univariate analysis, breakfast with "every day to skipping," physical activity with "active to inactive" and "with inactive to inactive, " sleep duration with "not short to short," TV viewing with " $\geq 3 \mathrm{~h}$ to $\geq 3 \mathrm{~h}$," BMI with "overweight to overweight," irritability with "rare to not rare" and with "not rare to not rare," and unwillingness to attend school with "not rare to not rare" were associated with constipation incidence. In the multivariate analysis, breakfast with "every day to skipping" (OR 1.73; 95\% CI, 1.20-2.49), physical activity with "active to inactive" (OR 1.55; 95\% CI, 1.14-2.11), BMI with "overweight to overweight" (OR 0.39; 95\% CI, 0.210.70 ), and irritability with "not rare to not rare" (OR 1.80; 95\% CI, 1.03-3.13) remained factors significantly associated with constipation incidence. Frequency of interaction with parents did not have a significant impact on adolescent constipation.

\section{Discussion}

Our prospective study showed that, among Japanese adolescents aged 12 to 13 years, the incidence rate of constipation, defined as bowel movements "less frequently than once every 2 days," was $4.7 \%$ over the 3 year period. Female sex, overweight (inversely), and infrequent consumption of fruits at baseline were significantly associated with adolescent constipation incidence. Furthermore, starting to skip breakfast, becoming physically inactive, and being persistently irritated were also associated with constipation incidence. Considering the fact that constipation is a common and persistent disease [19], our findings are valuable to decrease the burden of constipation in individuals and society. Our study was the first prospective study to demonstrate the incidence of adolescent constipation.

In our study, $6.8 \%$ of girls and $2.7 \%$ of boys developed constipation during the 3-year period (female OR 2.62, 
Table 2 Lifestyle, overweight, and psychological status at baseline and incidence of constipation

\begin{tabular}{|c|c|c|c|c|c|c|c|}
\hline & \multirow[t]{2}{*}{$\mathrm{n}=5540$} & \multirow{2}{*}{$\begin{array}{l}\text { constipation } \\
(\%)\end{array}$} & \multicolumn{2}{|c|}{ univariate } & \multicolumn{3}{|c|}{ multivariate } \\
\hline & & & OR & $95 \% \mathrm{Cl}$ & OR & $95 \% \mathrm{Cl}$ & $\mathbf{p}$ \\
\hline \multicolumn{2}{|l|}{ Female (/male) } & $6.8 / 2.7$ & 2.63 & $(2.01-3.45)$ & 2.62 & $(1.99-3.46)$ & $<0.001$ \\
\hline \multicolumn{2}{|c|}{ Skipping breakfast (/ every day) } & $5.2 / 4.7$ & 1.11 & $(0.68-1.82)$ & 1.05 & $(0.63-1.73)$ & 0.863 \\
\hline Sleep duration & $<8$ & 5.7 & 1.29 & $(0.78-2.16)$ & 1.28 & $(0.76-2.14)$ & 0.360 \\
\hline \multirow[t]{2}{*}{ (hour) } & $<9$ & 4.9 & 1.10 & $(0.85-1.42)$ & 1.09 & $(0.84-1.42)$ & 0.515 \\
\hline & 9 or more & 4.4 & 1 & & 1 & & \\
\hline Exercise & inactive(/ active) & $5.0 / 4.6$ & 1.09 & $(0.82-1.45)$ & 1.04 & $(0.77-1.4)$ & 0.790 \\
\hline TV viewing & $<2$ & 4.2 & 1 & & 1 & & \\
\hline \multirow[t]{2}{*}{ (hour) } & $<3$ & 5.7 & 1.36 & $(1.03-1.80)$ & 1.24 & $(0.93-1.64)$ & 0.140 \\
\hline & 3 or more & 5.2 & 1.25 & $(0.84-1.85)$ & 1.10 & $(0.74-1.65)$ & 0.633 \\
\hline Overweight & yes (/ no) & $3.1 / 5.0$ & 0.61 & $(0.40-0.92)$ & 0.60 & $(0.40-0.91)$ & 0.016 \\
\hline \multicolumn{2}{|c|}{ Fruits consumption, daily } & 4.0 & 1 & & 1 & & \\
\hline & 3-5 times/week & 4.9 & 1.23 & $(0.92-1.66)$ & 1.31 & $(0.97-1.78)$ & 0.082 \\
\hline & 0-2 times/week & 5.4 & 1.37 & $(1.00-1.87)$ & 1.50 & $(1.08-2.09)$ & 0.017 \\
\hline \multicolumn{2}{|c|}{ Vegetable consumption, daily } & 4.8 & 1 & & 1 & & \\
\hline & 3-5 times/week & 4.2 & 0.87 & $(0.64-1.18)$ & 0.80 & $(0.59-1.10)$ & 0.166 \\
\hline & 0-2 times/week & 5.3 & 1.12 & $(0.76-1.63)$ & 1.05 & $(0.71-1.56)$ & 0.814 \\
\hline \multirow[t]{3}{*}{ Irritability } & rare & 3.9 & 1 & & 1 & & \\
\hline & sometime & 4.8 & 1.24 & $(0.92-1.66)$ & 1.18 & $(0.88-1.60)$ & 0.269 \\
\hline & often & 6.1 & 1.59 & $(1.09-2.34)$ & 1.41 & $(0.94-2.12)$ & 0.101 \\
\hline \multicolumn{2}{|c|}{ Unwilling to attend school, rare } & 4.4 & & & 1 & & \\
\hline & sometime & 5.1 & 1.18 & $(0.90-1.55)$ & 1.09 & $(0.82-1.45)$ & 0.548 \\
\hline & often & 6.6 & 1.55 & $(0.99-2.44)$ & 1.47 & $(0.91-2.37)$ & 0.114 \\
\hline \multicolumn{2}{|c|}{ interaction with parents, often } & 5.2 & 1 & & 1 & & \\
\hline & sometime & 4.4 & 0.83 & $(0.61-1.13)$ & 0.87 & $(0.64-1.19)$ & 0.380 \\
\hline & rare & 4.8 & 0.91 & $(0.67-1.25)$ & 0.97 & $(0.70-1.35)$ & 0.874 \\
\hline
\end{tabular}

$O R$ odds ratio, $C l$ confidence interval

Variables with a significant relationship to constipation are shown in bold

Table 2), which seemed comparable to the results of many cross-sectional studies showing that female adults are more likely to be constipated than male adults, although sex differences in the prevalence of constipation among children have been inconsistent $[1,7,20,21]$. Some mechanisms of female predominance in constipation have been demonstrated. Total gut transit time was reported to be longer in women than in men [22]. Female sex hormones, such as progesterone, are thought to decrease the rate of small bowel and colonic transit times [23, 24].

The association between obesity or overweight and childhood constipation is inconsistent [25]. Previous studies conducted in clinical settings showed that children with functional constipation had a higher prevalence of obesity than controls [26, 27]. Meanwhile, most previous population-based studies for healthy children reported no association $[21,28]$ or an inverse association between obesity and constipation [8, 29, 30]. In our study, children who were overweight were less likely to develop constipation. One plausible explanation of this discrepancy is that children in population study may be less obese and have healthier bowel motility, i.e., which is more sensitive to food or a fecal mass than children studied in clinical settings.

The present study's results showed that infrequent consumption of fruits was associated with constipation incidence. Insufficient dietary fiber intake is considered a major risk factor for constipation [1, 7]. Fiber is known to exert a beneficial effect on constipation, because it provides a fecal bolus mass-incrementing effect, possesses water retention properties, increases colon bacteria and gas production, and accelerates colon transit time [31]. Our prospective study in community adolescents demonstrated for the first time that adolescents having infrequent fruit intake develop constipation. 
Table 3 Impact of changes in lifestyle, overweight, and psychological status on incidence of constipation

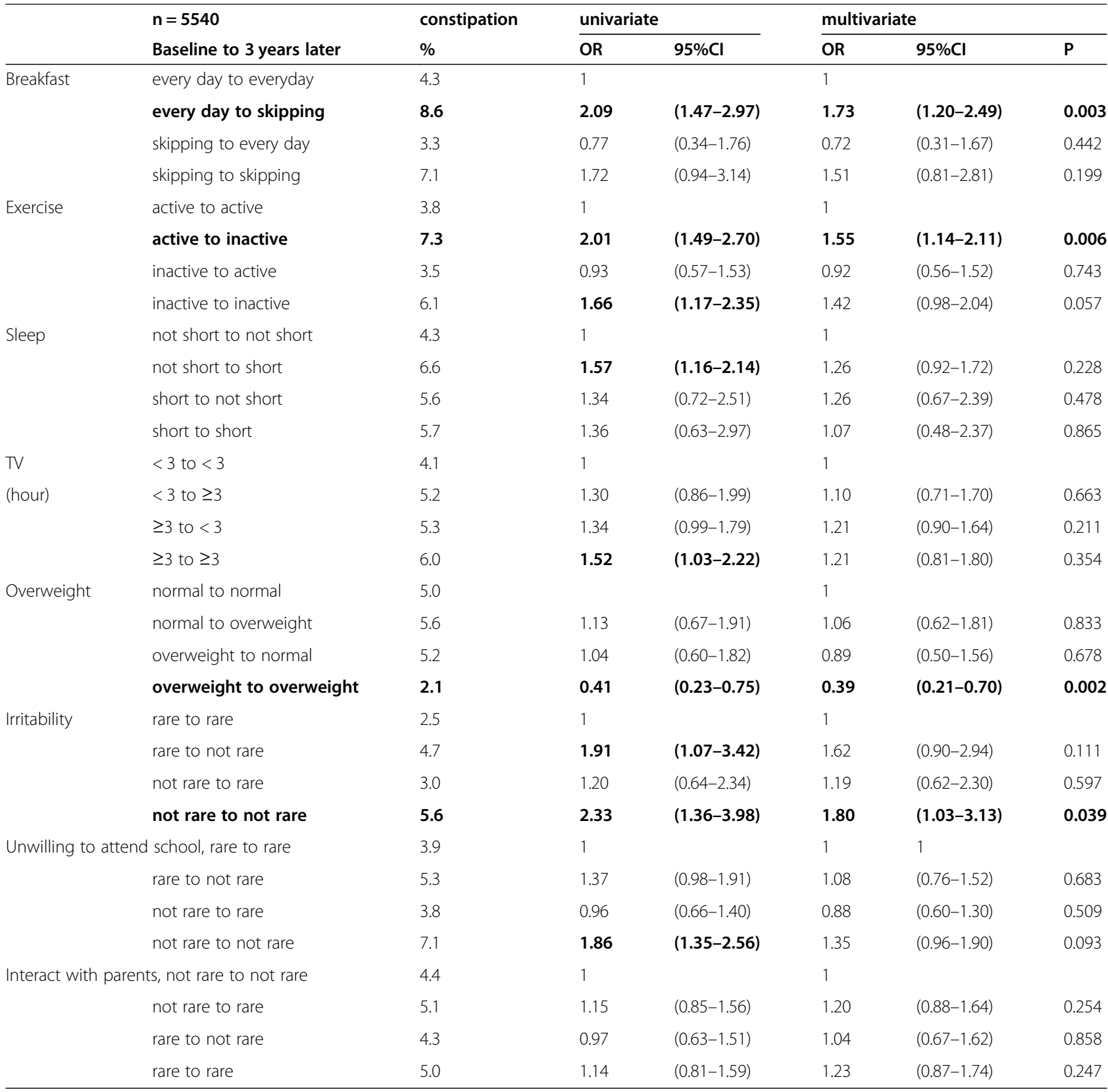

In multivariate model, sex and frequency of fruits and vegetable at baseline (phase 3 ) were also adjusted $O R$ odds ratio, $\mathrm{Cl}$ confidence interval

Variables with a significant relationship to constipation are shown in bold

Meanwhile, frequency of vegetable consumption did not predict constipation incidence in this study, which could be due to the following: first, most adolescents might have consumed vegetables almost every day at follow-up survey; thus, this questionnaire did not produce variance in our analysis; and second, fruit intake, rather than vegetable intake, might correspond more to actual fiber volume.

Notably, we focused on the impact of changes in lifestyle on constipation incidence (Table 3). Adolescents who started to skip breakfast during the three years were more likely to develop constipation. Similarly in previous cross-sectional studies in Japan, an association between skipping breakfast and constipation was reported in female college students [32, 33]. There have been several biological studies that can account for our result. Clock genes that form biological rhythms are functional in the liver, within gastrointestinal epithelial cells and neurons of the enteric nervous system [34]. Therefore, disruptions in circadian rhythmicity may lead to adverse health 
consequences [35]. In addition, Rao et al. conducted a study in healthy adults using manometry to investigate the motor activity of the colon [36]. The pressure waves in the colon during the night were inactive, but waking induced a threefold increase in motility, and meals induced a two-fold increase, proving that the ideal time for defecation would be after having breakfast in the morning. The importance of breakfast is not recognized as a predisposing factor of childhood constipation in recent reviews [1,7], our findings in this prospective study can recommend, not anecdotally, that adolescents should keep having breakfast every day to prevent constipation.

Adolescents who became physically inactive were also more likely to develop constipation. Physical inactivity has been associated with constipation in many studies $[1,7]$. The plausible mechanism by which physical activity modulates bowel movement is prolonged colonic transit time [37]. De Schryver et al. showed from their randomized controlled trial of 43 adults that subjects with programmed physical activity for 12 weeks have decreased rectosigmoid and total colonic transit time [38]. There were no significant associations between constipation and sleep duration or duration of TV viewing in the multivariate model. These factors may be confounded by other variables in our analyses.

Psychological stress, such as anxiety, irritability, infrequent parental interaction, and stressful life events, are well-known factors associated with childhood constipation $[7,8,39]$. To date, a large-scale study investigating the association between childhood constipation and psychological stress has been limited [40,41], and the most studies were cross-sectional or retrospective in nature $[1,7]$. We demonstrated that adolescents who had been persistently irritated more significantly developed constipation during the three years. Both adolescents who were irritated from grade 4 to grade 7 with "rare to not rare" and those with unwillingness to attend school "rare to not rare" and "not rare to not rare" were more likely to develop constipation. Contrary to the results from our cross-sectional study demonstrating that grade 4 children with infrequent child-parent interaction had a significant association with constipation [8], the frequency of the interaction showed no difference in the incidence of constipation. This discrepancy may be attributed to the psychological growth of adolescents. It may not be so important for adolescents to have frequent child-parent interactions compared to school-aged children. To prevent adolescent constipation, quality parental interactions that can mitigate adolescents' psychological stress, rather than quantity, is recommended.

\section{Limitations}

First, we conducted a questionnaire-based survey. Although obtaining psychological information from adolescents was a strength of this survey, it is subject to recall bias. Second, we did not collect information on gastrointestinal diseases and medication use. However, these conditions were not common among adolescents in the community. Third, other factors, such as genetic predisposition, volitional stool retention, menstruation, and microbiota were not included [42]. Finally, adolescents in our study were included from one prefecture in Japan. Thus, the results may differ in the general population because lifestyle factors such as diet and exercise are influenced by cultural differences. Further international, large-scale studies including these factors should be conducted.

\section{Conclusion}

Approximately $5 \%$ of adolescents developed constipation during the 3-year study period, and the incidence was especially high in female (6.8\%). Infrequent fruit intake, unhealthy lifestyle habits such as skipping breakfast and physical inactivity, and persistent psychological stress, were associated with the incidence of constipation. Beyond anecdotal evidence, maintaining a healthy lifestyle should be recommended for adolescents to prevent constipation. Additionally, health providers and parents should encourage adolescents to maintain a healthy lifestyle and avoid persistent psychological stress to reduce their risk of developing constipation.

\section{Supplementary Information}

The online version contains supplementary material available at https://doi. org/10.1186/s12889-020-10044-5.

Additional file 1. Questionnaire in Toyama Birth Cohort Study (Phase 3).

\section{Abbreviations}

BMI: Body mass index; OR: Odds ratio; Cl: Confidence internal; SPSS: Statistical package of social sciences

\section{Acknowledgments}

We express our great appreciation to all children and their parents participating in this study. We are indebted to the principals and school nurses in Toyama Prefecture for their help and co-operation in the study. We also acknowledge for the contribution of Ms. Yasuko Yamazaki for data collection and general management of this study.

\section{Authors' contributions}

All authors made substantial contributions in this manuscript that every author responsibility is specified in the following: MY was principal investigator and was responsible for conception and design of this study. MS, conducted the Toyama birth Cohort study and collected the data. MY and MS analyzed and interpreted the data. MS, TT and YF gave a critical review to this study. All authors read and approved the final manuscript.

\section{Funding}

The Toyama Birth Cohort Study has been supported by grants from the Ministry of Health and Welfare (H10-Child-020), the Ministry of health, Labour and Welfare (H13-Health-022), Toyama Medical Association, and the Japan Heart Foundation. The granting sources had no role in the design or conduct of the study; management, analysis, or interpretation of the data; or the preparation, review, or approval of manuscript. 


\section{Availability of data and materials}

The dataset analyzed during the current study are not publicly available due to ethical restrictions and specific legal framework in Japan. It is prohibited by the Act on the Protection of Personal Information (Act No. 57 of 30 May 2003, amended on 9 September 2015) to publicly deposit data containing personal information. However, data are available from the corresponding author on reasonable request.

\section{Ethics approval and consent to participate}

Our studies were approved from the Ethics Committee of Toyama Medical and Pharmaceutical University (current University of Toyama). We affirm that informed and written consent was obtained from all children and their parents. Our study was in accordance with the Helsinki Declaration of 1964 and later versions.

\section{Consent for publication}

Not applicable.

\section{Competing interests}

The authors declare that they have no competing interests.

\section{Author details}

'Department of Epidemiology and Health Policy, School of Medicine, University of Toyama, Toyama, Japan. 2630 Sugitani, Toyama 930-0194, Japan. ${ }^{2}$ Department of Community Medicine and Health Promotion, University of Toyama, Toyama, Japan. 2630 Sugitani, Toyama 930-0194, Japan.

\section{Received: 17 June 2020 Accepted: 10 December 2020}

Published online: 06 January 2021

\section{References}

1. Koppen IJN, Vriesman MH, Saps M, Rajindrajith S, Shi X, van Etten-Jamaludin FS, et al. Prevalence of Functional Defecation Disorders in Children: A Systematic Review and Meta-Analysis. J Pediatr. 2018;198:121-30.e6. https:// doi.org/10.1016/j.jpeds.2018.02.029.

2. Loening-Baucke. Constipation in early childhood: patient characteristics, treatment, and longterm follow up. Gut. 1993;34:1400-4.

3. Bongers ME, van Wijk MP, Reitsma JB, Benninga MA. Lon-term prognosis for childhood constipation: clinical outcomes in adulthood. Pediatrics. 2010;126: e156-62. https://doi.org/10.1542/peds.2009-1009.

4. Loening-Baucke V, Swidsinski A. Constipation as cause of acute abdominal pain in children. J Pediatr. 2007:151:666-9.

5. Vriesman MH, Rajindrajith $\mathrm{S}$, Koppen IJN, van Etten-Jamaludin FS, van Dijk M, Devanarayana NM, et al. Quality of life in children with functional constipation: a systematic review and meta-analysis. J Pediatr. 2019;214:14150. https://doi.org/10.1016/j.jpeds.2019.06.059.

6. Van Den Berg MM, Benninga MA, Di Lorenzo C. Epidemiology of childhood constipation: a systematic review. Am J Gastroenterol. 2006;101:2401-9.

7. Rajindrajith S, Devanarayana NM, Perera BJC, Benninga MA. Childhood constipation as an emerging public health problem. World J Gastroenterol. 2016;22:6864-75.

8. Yamada M, Sekine M, Tatsuse T. Psychological stress, family environment, and constipation in Japanese children: the Toyama birth cohort study. J Epidemiol. 2019;29(6):220-6.

9. Van Ginkel R, Reitsma JB, Büller HA, Van Wijk MP, Taminiau JAJM, Benninga MA. Childhood constipation: longitudinal follow-up beyond puberty. Gastroenterology. 2003:125:357-63.

10. Department of Health Promotion, Toyama Medical and Pharmaceutical University. Report of Toyama Birth Cohort Study Phase 3. Chuoinsatsu; 2001. (in Japanese).

11. Department of Health Promotion, Toyama Medical and Pharmaceutical University. Report of Toyama Birth Cohort Study Phase 4. Chuoinsatsu; 2003. (in Japanese).

12. Gaina A, Sekine M, Chandola T, Marmot M, Kagamimori S. Mother employment status and nutritional patterns in Japanese junior high schoolchildren. Int J Obes. 2009:33(7):753-7.

13. Yamada M, Sekine M, Tatsuse T. Lifestyle and bowel movements in school children: results from the Toyama birth cohort study. Pediatr Int. 2017:59: 604-13.
14. Japan Child and Family Research Institute. Almanac of data on Japanese children 2016. Tokyo: KTC Chuoh Publishig Co; 2016. (In Japanese).

15. Chen $X$, Sekine M, Hamanishi S, Wang H, Gaina A, Yamagami T, et al. Validation of a self-reported physical activity questionnaire for schoolchildren. J Epidemiol. 2003;13:278-87.

16. Gaina A, Sekine M, Chen X, Hamanish S, Kagamimori S. Sleep parameters recorded by Actiwatch in elementary school children and junior high school adolescents: schooldays vs weekends. Sleep Hypn. 2004;6:66-77.

17. Cole TJ, Bellizzi MC, Flegal KM, Dietz WH. Establishing a standard definition for child overweight and obesity worldwide: international survey. Br Med J. 2000;320:1240-3.

18. Lacy BE, Mearin F, Chang L, Chey WD, Lembo AJ, Simren M, et al. Bowel disorders. Gastroenterology. 2016;150:1393-407.

19. Pijpers MAM, Bongers MEJ, Benninga MA, Berger MY. Functional constipation in children: a systematic review on prognosis and predictive factors. J Pediatr Gastroenterol Nutr. 2010;50:256-68.

20. Mugie SM, Benninga MA, Di Lorenzo C. Epidemiology of constipation in children and adults: a systematic review. Best Pract Res Clin Gastroenterol. 2011:25(1):3-18.

21. Costa ML, Oliveira JN, Tahan S, Morais MB. Overweight and constipation in adolescents. BMC Gastroenterol. 2011;11:40. https://doi.org/10.1186/1471230X-11-40.

22. Southwell BR, Clarke MCC, Sutcliffe J, Hutson JM. Colonic transit studies: Normal values for adults and children with comparison of radiological and scintigraphic methods. Pediatr Surg Int. 2009;25(7):559-72.

23. Jung HK, Kim DY, Moon $\mathbb{H}$. Effects of gender and menstrual cycle on colonic transit time in healthy subjects. Korean J Intern Med. 2003;18(3): 181-6.

24. Wald A, Van Thiel DH, Hoechstetter L, Gavaler JS, Egler KM, Verm R, et al. Gastrointestinal transit: the effect of the menstrual cycle. Gastroenterology. 1981;80(6):1497-500.

25. Koppen IJN, Kuizenga-Wessel S, Saps M, Di Lorenzo C, Benninga MA, van Etten-Jamaludin FS, et al. Functional defecation disorders and excessive body weight: a systematic review. Pediatrics. 2016;138:e20161417. https:// doi.org/10.1542/peds.2016-1417.

26. Phatak UP, Pashankar DS. Prevalence of functional gastrointestinal disorders in obese and overweight children. Int J Obes. 2014;38(10):1324-7.

27. Pashankar DS. Increased prevalence of obesity in children with functional constipation evaluated in an academic medical center. Pediatrics. 2005;1 16: e377-80. https://doi.org/10.1542/peds.2005-0490.

28. Tam YH, Li AM, So HK, Shit KY, Pang KK, Wong YS, et al. Socioenvironmental factors associated with constipation in Hong Kong children and Rome III criteria. J Pediatr Gastroenterol Nutr. 2012;55:56-61.

29. Wu TC, Chen LK, Pan WH, Bin TR, Hwang SJ, Wu L, et al. Constipation in Taiwan elementary school students: a nationwide survey. J Chinese Med Assoc. 2011;74(2):57-61.

30. Roma E, Adamidis D, Nikolara R, Constantopoulos A, Messaritakis J. Diet and chronic constipation in children: the role of fiber. J Pediatr Gastroenterol Nutr. 1999;28(2):169-74.

31. Washington N, Harris M, Mussellwhite A, Spiller RC. Moderation of lactuloseinduced diarrhea by psyllium: effects on motility and fermentation. Am J Clin Nutr. 1998;67:317-21.

32. Fujiwara T, Nakata R. Skipping breakfast is associated with reproductive dysfunction in post-adolescent female college students. Appetite. 2010; 55(3):714-7.

33. Kishimoto M, Tanaka K. The relationship between defecation and life style in young women. Bull Mukogawa Women's Univ Nat Sci. 2008;56:121-6 (in Japanese).

34. Hoogerwerf WA. Role of biological rhythms in gastrointestinal health and disease. Rev Endocr Metab Disord. 2009:10(4):293-300.

35. Ohlsson B, Manjer J. Physical inactivity during leisure time and irregular meals are associated with functional gastrointestinal complaints in middleaged and elder subjects. Scand J Gastroenterol. 2016;51(11):1299-307.

36. Rao SSC, Sadeghi P, Beaty J, Kavlock R, Ackerson K. Ambulatory 24-h colonic manometry in healthy humans. Am J Physiol Liver Physiol. 2001;280:G62939. https://doi.org/10.1152/ajpgi.2001.280.4.G62.

37. Cho KO, Jo YJ, Song BK, Oh JW, Kim YS. Colon transit time according to physical activity and characteristics in south korean adults. World J Gastroenterol. 2013;19(4):550-5.

38. De Schryver AM, Keulemans YC, Peters HP, Akkermans LM, Smout AJ, De Vries WR, et al. Effects of regular physical activity on defecation pattern in 
middle-aged patients complaining of chronic constipation. Scand J Gastroenterol. 2005;40(4):422-9.

39. Devanarayana NM, Rajindrajith S. Association between constipation and stressful life events in a cohort of Sri Lankan children and adolescents. J Trop Pediatr. 2010;56:144-8. https://doi.org/10.1093/tropej/fmp077.

40. Joinson C, Grzeda MT, von Gontard A, Heron J. Psychosocial risks for constipation and soiling in primary school children. Eur Child Adolesc Psychiatry. 2019;28:203-10.

41. Oswari H, Alatas FS, Hegar B, Cheng W, Pramadyani A, Benninga MA, et al. Epidemiology of Paediatric constipation in Indonesia and its association with exposure to stressful life events. BMC Gastroenterol. 2018;18:146. https://doi.org/10.1186/s12876-018-0873-0.

42. Fayfman M, Flint K, Srinivasan S. Obesity, motility, diet, and intestinal microbiota-connecting the dots. Curr Gastroenterol Rep. 2019;21:15. https://doi.org/10.1007/s1 1894-019-0680-y.

\section{Publisher's Note}

Springer Nature remains neutral with regard to jurisdictional claims in published maps and institutional affiliations.

Ready to submit your research? Choose BMC and benefit from:

- fast, convenient online submission

- thorough peer review by experienced researchers in your field

- rapid publication on acceptance

- support for research data, including large and complex data types

- gold Open Access which fosters wider collaboration and increased citations

- maximum visibility for your research: over $100 \mathrm{M}$ website views per year

At BMC, research is always in progress.

Learn more biomedcentral.com/submissions 